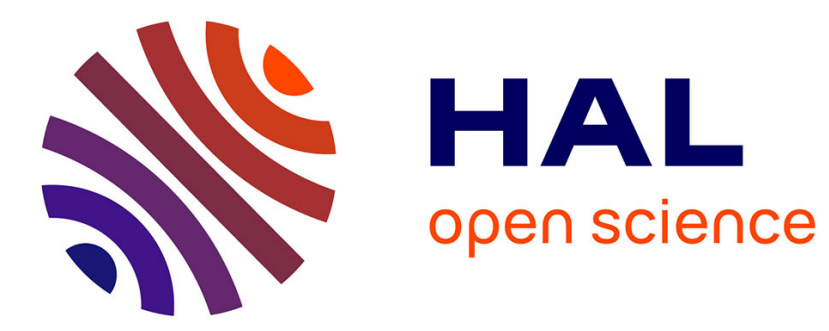

\title{
Emplacement of magma pulses and growth of magma bodies
}

\author{
Thierry Menand, Michel de Saint-Blanquat, Catherine Annen
}

\section{To cite this version:}

Thierry Menand, Michel de Saint-Blanquat, Catherine Annen. Emplacement of magma pulses and growth of magma bodies. Tectonophysics, 2011, 500 (1-4), pp.1-2. 10.1016/j.tecto.2010.05.014 . hal01146246

\section{HAL Id: hal-01146246 \\ https://hal.science/hal-01146246}

Submitted on 28 Apr 2015

HAL is a multi-disciplinary open access archive for the deposit and dissemination of scientific research documents, whether they are published or not. The documents may come from teaching and research institutions in France or abroad, or from public or private research centers.
L'archive ouverte pluridisciplinaire HAL, est destinée au dépôt et à la diffusion de documents scientifiques de niveau recherche, publiés ou non, émanant des établissements d'enseignement et de recherche français ou étrangers, des laboratoires publics ou privés. 


\section{Accepted Manuscript}

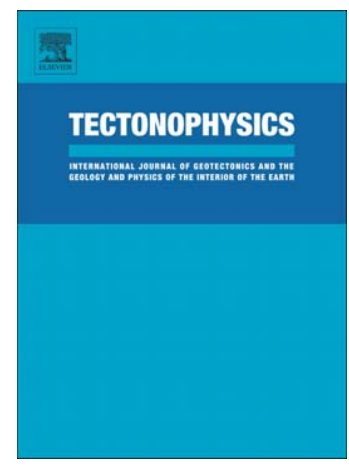

Emplacement of magma pulses and growth of magma bodies

Thierry Menand, Michel de Saint-Blanquat, Catherine Annen

PII: $\quad$ S0040-1951(10)00218-0

DOI: $\quad$ doi: $10.1016 /$ j.tecto.2010.05.014

Reference: $\quad$ TECTO 124932

To appear in: $\quad$ Tectonophysics

Received date: 10 May 2010

Accepted date: 18 May 2010

Please cite this article as: Menand, Thierry, de Saint-Blanquat, Michel, Annen, Catherine, Emplacement of magma pulses and growth of magma bodies, Tectonophysics (2010), doi: $10.1016 /$ j.tecto.2010.05.014

This is a PDF file of an unedited manuscript that has been accepted for publication. As a service to our customers we are providing this early version of the manuscript. The manuscript will undergo copyediting, typesetting, and review of the resulting proof before it is published in its final form. Please note that during the production process errors may be discovered which could affect the content, and all legal disclaimers that apply to the journal pertain. 


\section{Emplacement of magma pulses and growth of magma bodies}

Thierry Menand ${ }_{1}$, Michel de Saint-Blanquat 2 and Catherine Annen 1 ${ }_{1}$ University of Bristol, United-Kingdom (t.menand@bristol.ac.uk) ${ }_{2}$ CNRS - Université de Toulouse, France (michel@Imtg.obs-mip.fr)

\section{Introduction}

Magmatism is responsible for the formation of continental and oceanic crusts. It is the main agent of mass and heat transfers from the mantle towards the crust, the hydrosphere (oceanic and continental hydrothermalism) and the atmosphere (emissions of volcanic gas and ashes). Its expressions are the crystallization of intrusive rocks and the eruption of volcanic products. However, with a ratio between the volumes of extrusive and intrusive magmatic rocks estimated to be of the order of 1:5 for most magmatic systems (White et al., 2006), one of the main characteristics of magmatism is that magmas rarely reach the Earth's surface. This suggests that the prevailing conditions in the crust are not favourable to the arrival of magma on the Earth's surface, but instead lean heavily towards the formation of intrusive bodies in the crust. These intrusive bodies, referred to here as plutons, constitute the elementary building brick of the continental crust. An increasing number of geophyscial and geochronological data as well as geological observations is currently modifying our understanding of pluton construction. When plutons were initially envisaged as quasi-spherical bodies growing slowly and essentially by an overall inflation, they are now recognized as growing incrementally by the accretion of successive and relatively small magma pulses, over variable periods of time, from hundred to millions of years, depending on geodynamic setting and source fertility. This brings new challenges and has far-reaching implications. According to this new model of plutonism, the evolution of magma bodies is related to the processes that control the timescale and the spatial distribution of the successive pulses. Depending on their emplacement rate and on their ability to amalgamate, repeated magma pulses can either rapidly solidify or ultimately build up an active magma chamber. Thus understanding how magma bodies grow has fundamental implications for the link between volcanism and plutonism as well as for magma differentiation and ultimately for our understanding of the growth and evolution of the Earth crusts. The concept of pluton incremental growth challenges our understanding as well as our field interpretations of the processes involved during pluton construction. Indeed, these processes and how they operate in governing the emplacement and growth of plutons, both in space and time, are still debated.

A state-of-the-art session on these very issues was held at the 2008 General Assembly of the European Geosciences Union. As a follow-up of this session, this special volume Emplacement of magma pulses and growth of magma bodies brings together both theoretical models and field studies that cover most aspects of the emplacement and growth of plutons.

\section{This volume}

The volume starts with three reviews of the thermal, mechanical and structural aspects of the emplacement and construction of crustal magma bodies. Annen (this issue) reviews the thermal evolution of magma bodies growing by slow amalgamation of discrete pulses, and suggests that incremental growth could explain the bi-modal character of magmatic provinces with intermediate magmas resulting from the open nature of the systems through the mixing of both mafic ans silicic end-members. This review also supports a model of magma bodies construction as a multi-time-scale process with the development of large magma chambers corresponding to the 
highest magma fluxes, several orders of magnitude higher than the average pluton emplacement rate. Menand (this issue) then reviews the different mechanisms controlling the formation and emplacement depths of sills, and how these can amalgamate to form larger igneous bodies. The main conclusion of this review is that the dominant control on sill emplacement is exerted by crustal heterogeneities via their rigidity and rheological anisotropy, and their interaction with the local and tectonic stress fields. In turn, this determines whether and how successive sills can amalgamate to form larger magma bodies. Finally,

Saint Blanquat et al. (this issue) review the mechanisms and duration of pluton construction in continental magmatic arcs. Field studies on plutons of various sizes (from 1 to more than 1000 $\mathrm{km}_{3}$ ) show that each pluton size is related to a pulsed magmatic activity with a characteristic time scale, and that each of these coupled time-space scales is related to a specific process. High magma fluxes relative to crustal tectonic strain rates ensure that magmatic processes control the system from below. One of the main consequences is that for high fluxes or over short time scales the dynamics of the pulsed magmatism observed in continental arc plutonic systems are a direct proxy for deep lithospheric and magmatic processes. These reviews are complemented by two thermal and mechanical studies. First, Michaut and Jaupart (this issue) discuss two thermal models for the formation of magma reservoirs by small increments. The authors show that if a magma body grows by amalgamation of relatively thick individual igneous sheets, crystallization in that body proceeds at equilibrium as described by Annen (this issue). If the body grows instead by amalgamation of relatively thin sheets, the thermal evolution of the body is kinetically controlled such that the initial sheets do not crystallize completely but instead preserve a glassy residue. As the temperature of the system subsequently increases, devitrification of this glass occurs which leads crystallization to proceeds catastrophically in a positive feedback loop involving latent heat release and temperature rise. These two thermal models have different implications for the formation of magma chambers as well as the amount of melt generated. Then, Gudmundsson (this issue) discusses the mechanisms for the arrest of dykes and their deflection into sills at discontinuities in the upper crust in relation to the formation of shallow plutons and magma chambers. The emphasis is put on the role of hostrock layering and three associated mechanisms for the arrest of dykes and their deflection into sills. The Cook-Gordon mechanism corresponds to a weak contact that opens up as a result of tensile stresses induced by a nearby dyke, a mechanism that is likely to operate primarily at shallow crustal depths. A second mechanism is the development of stress barriers, which occurs within rock layers where the minimum compressive stress becomes vertical and thus opposes the advance of dykes and favours sill emplacement. In the third mechanism, adjacent layers with different elastic properties can lead to material-toughness ratios that are favourable to sill formation. This situation is most likely to arise when a rock layer is stiffer than the one underneath, such as in the case of a relatively stiff lava flow overlying comparatively a softer pyroclastic layer; a propagating dyke would then have a greater tendency to be deflected into the contact between the adjacent rock layers. The volume closes with four field-based studies that cover a range of pluton emplacement settings, sizes and localities. They also illustrate the challenges faced when interpreting field observations in the light of our improved understanding of pluton emplacement and growth. Numerous evidence suggest and support an incremental growth of plutons. Yet well-defined contacts within plutons remain commonly elusive. Miller et al. (this issue) compare and contrast the structural and zircon features of the Spirit Mountain batholith and the smaller Aztec Wash pluton in southern Nevada, USA, to explain this discrepancy. Both are proposed to have grown by magma replenishments and sheet-stacking into low-strength mush zones, but the contacts between successive sheets would have disappeared gradually owing to the continuous increase in magma content and heat during their growth. According to Miller et al. (this issue), the smaller Aztec Wash pluton retained a more diverse composition and texture because of its smaller volume and history, whereas a much more protracted history lead to a much larger and more homogenized 
Spirit Mountain batholith except for the latest stage of its construction. This interpretation explains not only the apparent contradiction between incremental and protracted pluton growth and a seeming absence of intrusive contacts, but is also consistent with the recent thermal models exposed in this special volume on the thermal evolution of plutons growing by amalgamation of sills and the conditions for the existence of long-lived shallow crustal magma chambers (Annen this issue; Michaut and Jaupart, this issue). Allibon et al. (this issue) document a rare example of a pluton located in the oceanic crust which could be interpreted as a feeder of the Fuerteventura volcano, in Canary Islands. It is a vertically layered mafic dyke-like pluton constructed in a transtensive tectonic environment. The structural features of the pluton attest of an incremental growth by periodic injections and amalgamations of dykes similar to a sheeted-dyke complex, and the authors interpret this emplacement geometry as controlled by the extensional regional tectonic setting that prevailed during the Miocene pluton growth. The authors attribute also the observed sequence of internal differentiation of individual dykes, their subsequent compaction and the migration of interstitial melt that followed, as reflecting the interplay between the regional tectonic setting and the rate and volume of the successive dyke injections that were controlled instead by source-related processes. Paterson et al. (this issue) review field, geochronological and geochemical data from North America and Mongolia to constraint the size, geometry and duration of magma chambers resulting form incremental construction. This study stresses the importance of both intrusive rates and pulse sizes on the spatial and temporal characteristics of magma chambers, and so on the relationship between plutonism and volcanism, and thus echoes other theoretical studies presented in this volume (Annen, this issue; Michaud and Jaupart; this issue) that large, long-lived magma chambers can exist but their volumes and lifetime are strongly dependent on intrusive rates, their temporal variation and their spatial distribution. Finally, Marko and Yoshinobu (this issue) document the structural and thermal aureoles o the White Horse Pluton in eastern Nevada, USA. The authors use the structures of the contact aureole to show both spatial and temporal variations in the rheology of the host rocks associated with the repeated injections of magma that lead to the formation of the pluton, and thus to constrain the temporal and spatial construction of this pluton. The authors show evidences of both ductile and brittle deformation within the contact aureole, and that brittle deformation occurred in the late stage of the pluton construction following previous episode of ductile deformation. Additionally, the authors place geometric constraints on the shape and growth of the White Horse Pluton, and their estimates of the strain associated with the pluton growth suggest that shortening of the contact aureole could accounts for half the space created during the pluton formation. Other deformation mechanisms are thus required to account for the remaining space created during pluton emplacement. Our understanding of pluton construction is sharpening, and we hope this special volume Emplacement of magma pulses and growth of magma bodies provides a balanced and critical overview of our current knowledge of the incremental growth of plutons. With a set of both theoretical models and field studies that, we think, covers most aspects of the emplacement and growth of plutons, we also hope that this volume will be of interest for both the volcanic and plutonic communities, including theoreticians, field geologists and petrologists.

\section{Acknowledgments}

We would like to acknowledge the effort and expertise of all the reviewers who helped us for this volume: Pierre Barbey, Keith Benn, George Bergantz, Barrie Clarke, Sandy Cruden, Jo Dufek,

Adelina Geyer, Agust Gudmundsson, Olivier Merle, Calvin F Miller, Philippe Olivier, Alessandro Tibaldi, Jean-Louis Vigneresse, Roberto Weinberg, Robert Wiebe.

Furthermore, we would like to thank the editorial support from Mike Sandiford, Mian Liu, Andrés Villavicencio, Tim Horscroft, Frank Wang, Sheilagh Douma and Yvonne Philippo. 


\section{References}

White S.M., Crisp J.A., and Spera F.J., 2006. Long-term volumetric eruption rates and magma budgets. Geochemistry, Geophysics, Geosystems, 7, Q03010, doi:10.1029/2005GC001002. 